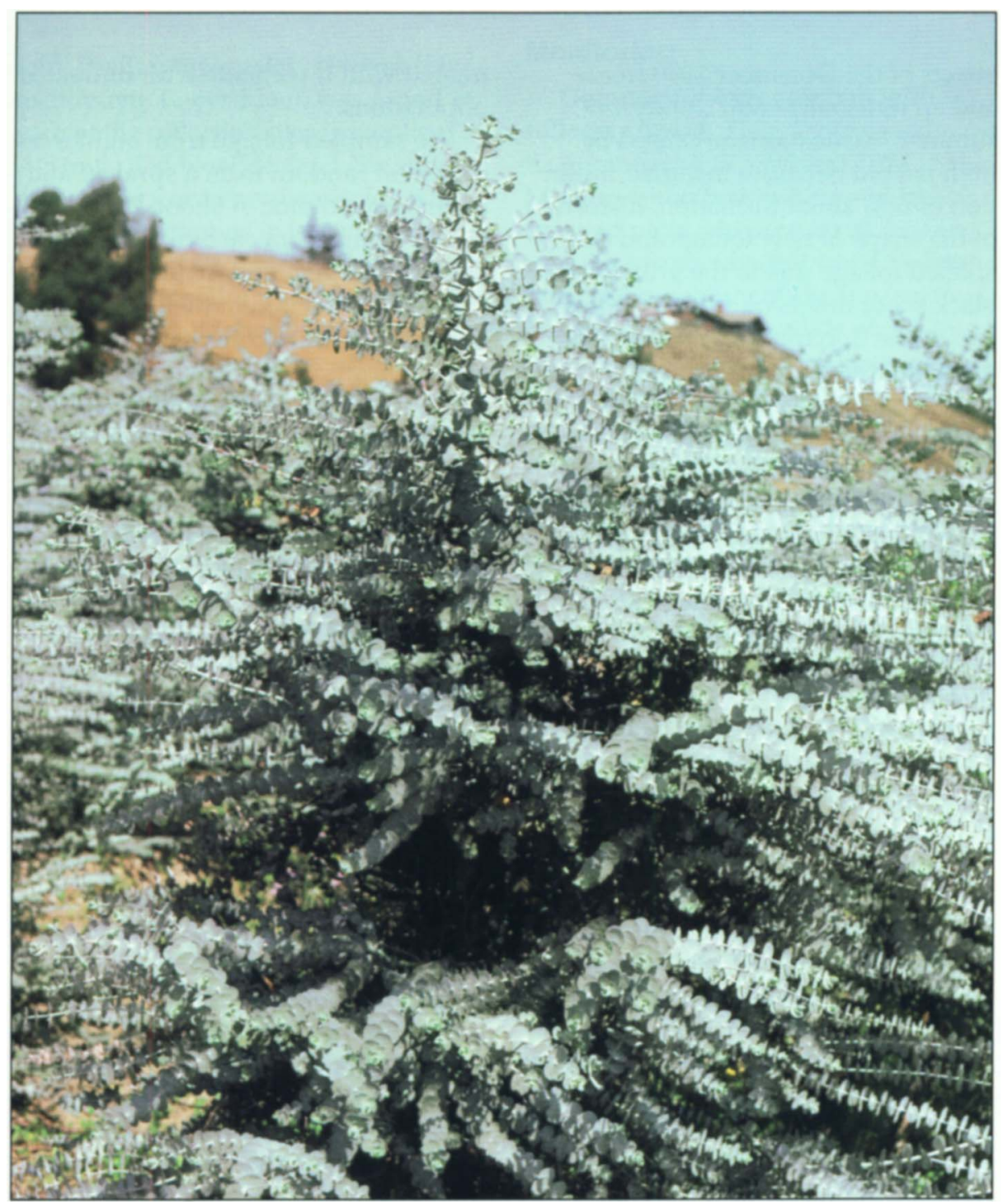

\title{
Parasitoid wasp controls blue gum psyllid
}

\author{
Donald L. Dahlsten D David L. Rowney $\square \quad$ William A. Copper \\ Richard L. Tassan \ William E. Chaney $\square$ Karen L. Robb \\ Steven Tjosvold $\square$ Mary Bianchi $\square$ Priscilla Lane
}

The blue gum psyllid was first discovered in North America in Monterey County in January 1991. Since then it has quickly spread throughout the California coastal area and has became a major pest on Eucalyptus pulverulenta in commercial foliage plantations. Large amounts of pesticides have been used to control the psyllid in these plantations. A primary parasitoid wasp, Psyllaephagus pilosus Noyes (Hymenoptera: Encyrtidae), was found in Australia and New Zealand and released at eight sites in California in spring/summer 1993. As a result, psyllid populations declined somewhat at most sites in 1993, and in 1994 psyllids were no longer a problem. The parasitoid has spread rapidly to other coastal areas.

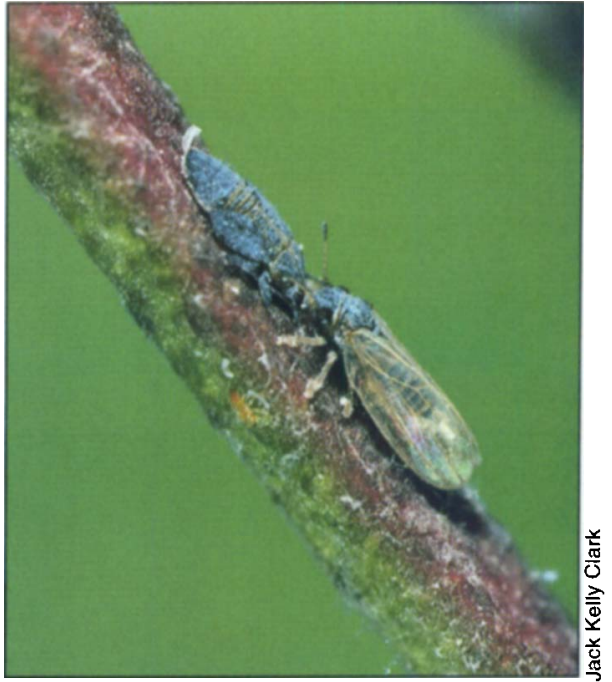

$\Delta$ High densities of the blue gum psyllid can inhibit new shoot formation, distort the shape of new foliage and despoil foliage with white flocculate secretions produced by the immature stages and black sooty molds that grow on the honeydew.

4 The blue gum psyllid was first found in a plantation of baby blue gum in Monterey County.

The blue gum psyllid, Ctenarytaina eucalypti (Maskell) (Homoptera: Psyllidae) is a pest new to North America. It was first found in Monterey County in January 1991 on silver-leaved mountain gum or baby blue gum, E. pulverulenta Sims (Gill 1991). Since then, it has been collected on E. pulverulenta and blue gum, $E$. globulus, in 12 other California counties (Gill 1991; Gill, personal communication). In California the psyllid has also been found on E. cinerea, $E$. glaucescens, E. camaldulensis (C2 clone) and $E$. viminalis.

So far the major impact has been on the baby blue gum cut-foliage plantations. Prior to 1991, pesticides were rarely if ever applied to commercially grown eucalyptus. In an effort to control the psyllid, growers made multiple applications of a variety of insecticides by ground rig or helicopter. However, these applications provided only a temporary reduction of psyllid numbers. Insecticide intervention has become an added expense to production costs (about $\$ 45 /$ acre per ground application and $\$ 100 /$ acre per helicopter application). In addition, many plantations are in the immediate prox- 


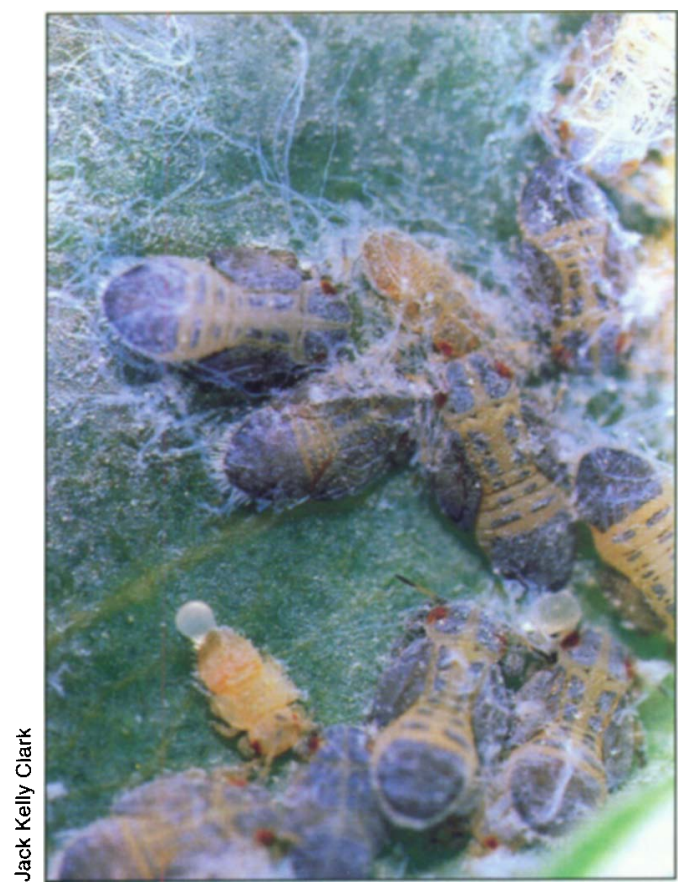

Nymphs of the blue gum psyllid on baby blue gum foliage exude waxy secretions.

Psyllaephagus pilosus, the tiny primary parasitoid of the blue gum psyllid, controlled the pest at all of the release sites and outside of the original release sites.

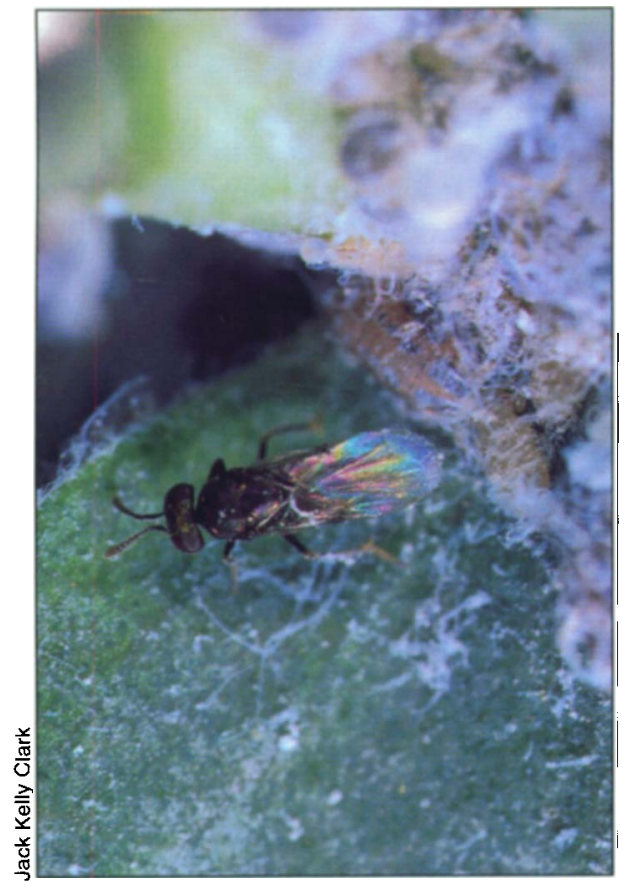

imity of urban development, which intensifies the issues of pesticide drift and public safety.

Growers reported a $30 \%$ reduction in the 1991 Eucalyptus cut foliage harvest, valued at approximately $\$ 30 \mathrm{mil}-$ lion statewide. They attributed the losses to the psyllid and, in the northern part of the state, to the combined effects of the December 1990 freeze and an unusually cool, cloudy 1991 summer. Acute damage caused by high psyllid densities included inhibition of new shoot formation, distortion of the shape of new foliage and despoiled foliage due to the growth of black sooty molds on the honeydew and white flocculate secretions produced by the immature stages.

The blue gum psyllid is native to Australia (Taylor 1990) but has been accidentally introduced to other regions of the world where eucalyptus is grown, including New Zealand, Sri Lanka, South Africa and Europe. Most information regarding the biology of the blue gum psyllid, its spread and its potential for damage comes from the European literature (Alma and Arzone 1988; Azevedo and Figo 1979; Cadahia 1980 and 1986; Cadahia and Ruperez 1979; and Martinez 1983).

Blue gum psyllid in Australia doesn't reach economically important levels, presumably because they are under natural biological control, and therefore have not attracted the attention of Australian entomologists. Also, blue gum is not grown commercially for foliage in Australia. The only reference that mentions the blue gum psyllid in Australia (Morgan 1984) supports this premise: "The insect is very common but rarely develops outbreaks. ..." and "It is heavily parasitized in the 5th instar and predators, particularly honeyeaters (birds), have been observed feeding upon nymphs and adults." Wilson (1963) noted that in New Zealand a eulophid (actually an encrytid), apparently also introduced, controls the psyllid.

The blue gum psyllid is a good candidate for a classical biological control program to reduce, if not eliminate, growers' reliance on insecticides, substantially save expenses and reduce adverse environmental impacts.

\section{Sampling psyllids, natural enemies}

The objectives of our 1991 study in Monterey County were to (1) develop sampling methods to monitor blue gum psyllid phenology prior to the parasitoid introduction; (2) identify and measure the effectiveness of endemic natural enemies; and (3) compare treatment effects on populations treated with insecticide with untreated populations.

We sampled foliage from eight trees chosen at random from a sprayed and an unsprayed plot. A shoot, 5 inches $(12 \mathrm{~cm})$ long, from each cardinal direction in the upper crown and a shoot from each direction in the lower crown on each tree were collected individually in plastic bags. The shoots were run through a mite-brushing machine, which knocks all stages of the blue gum psyllid from the foliage onto a sticky plate that is easily examined under a microscope. The contents of the bag, psyllid life stages and adult parasitoids by sex were recorded. In 1992 we eliminated the four lower crown samples per tree and expanded the number of trees per plot to 10 .

In 1992 we used sticky traps to monitor adult psyllids and natural enemies. Trap monitoring sites were established in northern (Monterey County), central (San Luis Obispo County) and southern (San Diego County) California. Foliage sampling was continued at two sites in Monterey County. In mid-1993 another site for both sticky traps and foliage sampling was added in Sonoma County. To determine effects distant from the release sites, one additional site in Monterey County was sampled with sticky traps in 1994 and two (in San Diego County and San Luis Obispo County) in 1995.

Sticky traps are 4-inch-diameter $(10 \mathrm{~cm})$ clear plastic lids coated with a high-viscosity motor oil additive on the outer surface. The coated lid is placed over a second fluorescent-yellow-painted backing lid without a lip. The two lids are held together with small binder clips. Stakes are driven into the ground along the rows of trees, and the yellow backing lids are attached to the stakes at 5 feet $(1.5 \mathrm{~m})$ height. The sticky trap lids were replaced each week for counting in the lab. Each of the plots had 10 sticky traps at random locations throughout the plot. In plots where foliage samples were taken, traps were adjacent to each of the foliage sample trees.

\section{Biological control}

During late 1991 and early 1992, only one species of the primary parasi- 
toid, Psyllaephagus pilosus Noyes (Hymenoptera: Encyrtidae), was found in each of the collection sites in southern Australia and New Zealand. Six species of secondary or hyperparasitoids were reared in quarantine in low numbers.

$P$. pilosus is a solitary, internal parasitoid of the psyllid nymphs. The adults are small (about $1 \mathrm{~mm}$ ) and black, with a hint of green iridescence. They are active searchers and readily fly. The female deposits a single egg inside the late instar psyllid nymph. After about 3 weeks at $77^{\circ} \mathrm{F}\left(25^{\circ} \mathrm{C}\right)$, development is complete and the new adult emerges from a hole chewed in the dorsum of the psyllid mummy. The female also host feeds on the body fluids that exude from holes made in young psyllid nymphs with her ovipositor.

We shipped parasitized psyllids to our Albany (Alameda County) quarantine facility and made initial releases of 50 adult parasitoids at this location in early 1993. When psyllid nymphs were abundant in Monterey County, 450 parasitoid adults were released in an unsprayed E. pulverulenta plot in spring 1993. Between May and September, about 6,000 adults were collected and released in San Luis Obispo (two sites), San Diego (two sites) and Sonoma (one site) counties. The source for all the releases was from Psyllaephagus in blue gum psyllids on E. globulus from the north island of New Zealand.

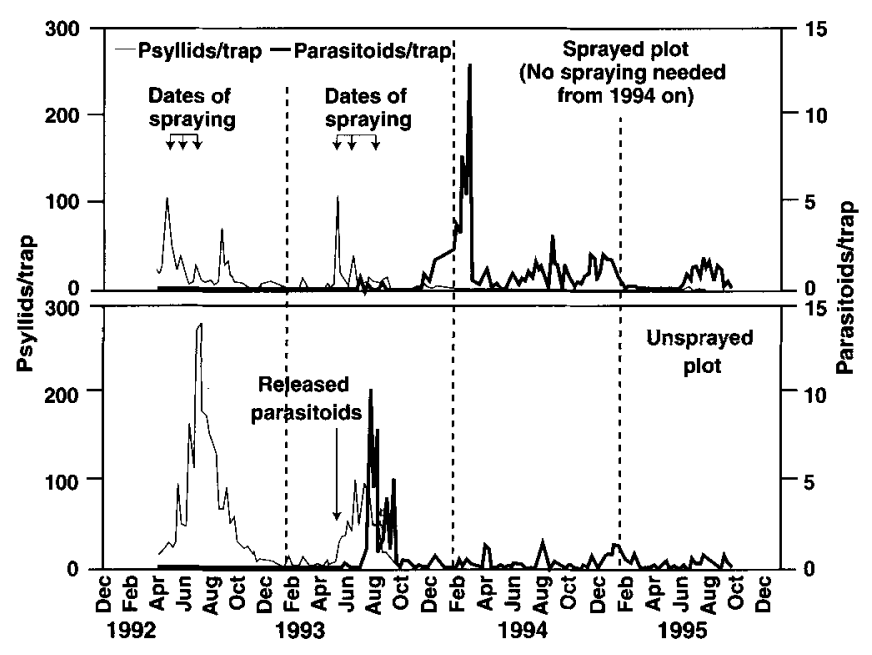

Fig. 1. Mean number of blue gum psyllid adults and parasitoid adults per sticky trap with standard errors for 4 years of weekly monitoring at Monterey County, Plantation one, sprayed plot (plot not sprayed in 1994 and 1995) and unsprayed plot.

\section{Monitoring}

Comparing trap catches with

foliage counts. Data for triweekly foliage sampling in 1993 and 1994 in the Monterey and Sonoma county unsprayed plots was compared to sticky trap data from adjacent traps to determine the reliability of the trap method. Weekly catches of psyllids on sticky traps reflected psyllid adult activity. Adult catch was correlated to psyllid density on foliage; the best relationship was between psyllid eggs per sample shoot and mean number of psyllid adult females captured per trap for the week preceding the foliage sample (Pearson correlation coefficient $r=0.91, n=43$ ). A regression equation can be calculated (assuming female adults per trap to be an index without variability) that gives a prediction of psyllid eggs per 5-inch $(12 \mathrm{~cm})$ shoot based on females per trap:

eggs $/$ shoot $=11.9+6.0 \times($ adult females/trap).

For example, 50 adult females caught indicates that in the subsequent week an average of about 312 eggs per shoot will be present in the foliage.

Rate of distribution through time in Monterey County plots. The pattern of psyllid adult activity in the baby blue gum plantations is illustrated by the trap catches in the sprayed and unsprayed plots in Monterey County (fig. 1). These plots were harvested in late fall to early spring, and new shoots began to grow significantly from April to May. Psyllid levels began to increase significantly at this time, peaking in 1992 around July, then falling off gradually to low levels by November. In the sprayed plot, psyllid numbers dropped after each spray and then rebounded between sprays. Psyllid damage to foliage still occurred in the sprayed plot, but at a reduced level. After 505 parasitoids were released in April 1993 in the

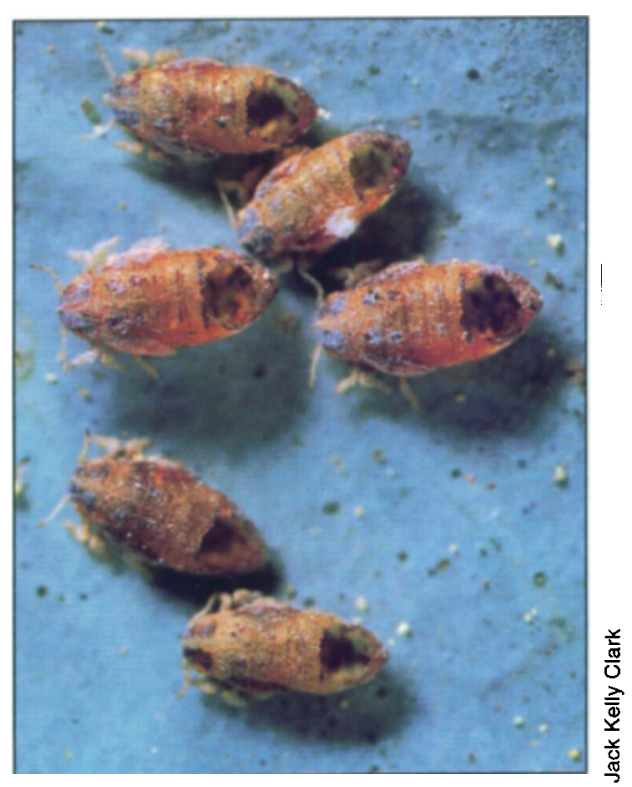

A group of blue gum psyllid mummies from which adult parasitic wasps have emerged.

unsprayed plot, psyllid populations increased but catches also showed a significant increase of parasitoids in July, and the peak psyllid level was about one-third lower compared to the previous July. Psyllid catch declined to near zero by late September in this plot. In the sprayed plot, a few parasitoids began to be caught in July and August 1993, and their numbers significantly increased in December 1993. We now had a sprayed plot with parasitoids and an unsprayed parasitoid release plot. A third control plot without either would have been desirable, but was impractical at this location due to the highly mobile nature of the parasitoid.

In 1994, in contrast to 1992 and 1993, psyllid trap catches (fig. 1) did not increase significantly in late spring/early summer at either plot. Throughout the summer, psyllid populations remained at very low levels seen previously only during periods with no significant foliage growth. Catches of parasitoids were frequently higher than catches of psyllids (fig. 1). Foliage samples in 1994 showed very few large psyllid nymphs, of which $50 \%$ to $100 \%$ were parasitized. As parasitoids reduced psyllid density below economic injury level, no spraying was needed. In 1995 the pattern for 1994 essentially repeated itself, with very low psyllid catches in traps and 
$50 \%$ or more parasitization of psyllid nymphs. In the unsprayed plot, parasitoid numbers were similar to numbers in 1994, but slightly lower than in the original sprayed plot.

Peak numbers per trap, all sites surveyed. In addition to the Monterey County plots described earlier, we sampled seven other plots on five $E$. pulverulenta farms in San Luis Obispo, San Diego, Sonoma and Monterey counties. The peaks for weekly mean values of adult psyllids per sticky trap show a steady decline in numbers for all plots after the 1993 release. The ratios of psyllid peak numbers in 1995 to the high of the prerelease or release years ranged from 1:25 to 1:197. Peak values for parasitoids per trap increased for most release plots from the 1993 release year to 1994, corresponding to the decline of the psyllids. By 1995 peak numbers of psyllids and parasitoids were similar in absolute value for all E. pulverulenta plots.

We sampled two plots of E. globulus in ornamental stands in Monterey and San Luis Obispo counties. At both, prerelease peak numbers of psyllids per trap tended to be somewhat higher (300 to 600 per trap) and to occur several months earlier in the spring than the peaks for E. pulverulenta plots. Ratios of peak psyllids in 1995 to the highest prerelease or release year were somewhat lower than for the for $E$. pulverulenta plots (1:41 in Monterey and 1:11 in San Luis Obispo). Peak numbers of parasitoids were higher in these plots than in most E. pulverulenta plots, and occurred earlier in the year. Parasitoid populations may be building up on E. globulus in the early spring and then moving to $E$. pulverulenta in early summer when psyllids become plentiful there.

Parasitoid spread. In April 1994 we began monitoring at a Monterey County E. pulverulenta plantation about 10 miles $(16 \mathrm{~km}$ ) from the initial 1993 release point. Populations of psyllids at this plantation were very high in May 1994 (peak nearly 1,000 times higher than at the Monterey $E$. pulverulenta plantation where parasitoids had been released). Parasitoids had spread naturally to this site by April 1994, but were present in only very low numbers initially; as the summer progressed, parasitoids increased rapidly as psyllid numbers fell to near zero in August.

By 1995 psyllid numbers were very low at this new sample site and no spraying was needed; peak psyllid counts were down by a factor of 65 and parasitoids appeared in moderate numbers.

In April 1994 we also found parasitoids in Monterey County about 33 miles $(53 \mathrm{~km})$ from the release site.

In 1995 we monitored two new baby blue gum plantations distant from two previous release areas. The new site in San Luis Obispo County (unsprayed, 4 miles [ $6 \mathrm{~km}$ ] from the release site) had very low peak psyllid numbers (2.3 per trap) and more parasitoids (9.9 per trap) than psyllids. The other nonrelease site in San Diego County (unsprayed, 11 miles [17 km] from the release site) was similar, with peaks of 1.9 psyllids per trap and 3.3 parasitoids per trap.

In 1994 and 1995 we recovered parasitoids in several California counties outside of the original release sites, including Contra Costa, Orange, San Joaquin, Santa Clara, San Mateo, Sacramento and Ventura counties. We have one reported recovery from Seattle, Wash.

\section{Conclusions}

Successful biological control of the blue gum psyllid has been achieved. The parasitoid Psyllaephagus pilosus is successfully controlling psyllid populations in all release areas, as well as in nearby nonrelease areas. Psyllid levels in 1994 and 1995 were well below levels achieved previously with spray treatments, and did not cause economic damage. For 2 years no pesticides have been needed for psyllid control in counties where releases were made.

The monitoring system using sticky trap counts that relate to psyllid eggs on foliage will save eucalyptus growers a great deal of money in pesticide applications by allowing them to detect both psyllid and parasitoid abundance.

Cooperative Extension personnel connected with this project are introducing methods developed by this study to other areas of California.
D.L. Dahlsten is Professor, D.L. Rowney is Biostatistician and W.A. Copper and R.L. Tassan are Staff Research Associates, College of Natural Resources, Center for Biological Control, UC Berkeley; W.E. Chaney, K.L. Robb, S. Tjosvold and M. Bianchi are Farm Advisors, UC Cooperative Extension, Monterey, San Diego, Santa Cruz and San Luis Obispo counties, respectively; and $P$. Lane is Entomologist, Sonoma County Department of Agriculture.

The authors appreciate the assistance of M.L. Schmidt, Laboratory Assistant, UC Berkeley; L.E. Caltagirone and the late K.S. Hagen, Professors Emeriti, Center for Biological Control, UC Berkeley; and R.F. Luck, Professor, Department of Entomology, UC Riverside.

This project was funded by the Eucalyptus Growers Association, the California Cut Flower Commission, the American Floral Endowment and UC Statewide Integrated Pest Management Project, Davis.

\section{References}

Alma A, Arzone A. 1988. Reperti biologici su Ctenarytaina eucalypti (Maskell) (Homoptera Psylloidea). Atti XV Congr naz ital Ent, L'Aquila p. 505-12.

Azevedo F, Figo ML. 1979. Ctenarytaina eucalypti Mask (Homoptera, Psyllidae). Bol Serv Plagas 5:41-6.

Cadahia D. 1980. Proximidad de dos nuevos enemigos de los Eucalyptus en España. Bol Serv Plagas 6:165-192.

Cadahia D. 1986. Importance des insectes ravageurs de l'eucalyptus en region mediterraneenne. Bulletin OEPP 16:265-83.

Cadahia D Ruperez A. 1979. Reparticion de Ctenarytaina eucalypti Mask en España.

Bol Serv Plagas 5:55-8.

Gill R. 1991. California plant pest and disease report. California Department of Food and Agriculture 10:57.

Martinez M. 1983. Possibilite d'introduction en France de deux insectes ravageurs specifiques des Eucalyptus: Phoracantha semipunctata [Col.

Cerambycidae] et $\mathrm{Ct}$ [Hom. Psyllidae]

L'Entomolgiste 39:53-7.

Morgan FD. 1984. Handbook of the flora and fauna of South Australia. Psylloidea of South Australia. Government Printer, South Australia. $136 \mathrm{p}$.

Taylor KL. 1990. The tribe Ctenarytainini (Hemiptera: Psylloidea): A key to the known Australian genera, with new species and two new genera. Invertebr Taxon 4:95-121.

Wilson F. 1963. Australia as a source of beneficial insects for biological control. Technical Communication No. 3, Commonwealth Institute of Biological Control, Curepe,

Trinidad. $18 \mathrm{p}$ 